\title{
THE ESTABLISHMENT OF SURGICAL PRINCIPLES IN THE TREATMENT OF FRACTURE OF THE NECK OF THE FEMUR
}

ARMITAGE WHITMAN, M.D.

Assistant Surgeon to Outpatients, Hospital for the Ruptured and Crippled; Orthopedic Surgeon to Lincoln Hospital and to the

Booth Memorial Hospital

NEW YORK

In reviewing the general literature on the subject of fractures and their treatment, one is impressed with the fact that one injury, and only one, is regarded as a hopeless proposition-fracture of the neck of the femur. The more modern authors mention various forms of treatment and concede the possibility of the union of such a fracture, but the general tone adopted is one of discouragement and disillusionment. In one of our best known textbooks, ${ }^{1}$ the section on treatment of this injury begins: "The first indication is to save life." In the section on fractures of the skull and of the pelvis, notably grave conditions, the author says nothing about life saving as a primary indication for treatment. Indeed, one would suppose that life saving was the essential preliminary to any treatment, and that it might be taken for granted. Why, then, is its necessity emphasized in connection with this one injury?

In answering this question, one must review the history of the injury. I take as my premise that fracture of the neck of the femur is now very generally regarded as: (1) an injury of advanced age; (2) an injury for which there is no standard treatment, and, (3) an injury differing from others in that the impression is widely prevalent that an intracapsular fracture of the neck of the femur is per se incapable of repair.

It is extraordinary that one bone in the skeleton should be distinguished for its lack of a characteristic accorded to all others. As an explanation of this invidious distinction, I can do no better than to quote at length from the author whose opinion, wrongly, I believe, has always been adduced in support of the proposition that intracapsular fracture of the neck of the femur could not unite. ${ }^{2}$ Sir Astley Cooper ${ }^{2}$ said:

1. Stimson, L. J.: Fractures and Dislocations, Ed. 6, Philadelphia, Lea \& Febiger, 1910, p. 354.

2. Cooper, Astley: Dislocations and Fractures, Ed. 1, London, John Churchill, 1822. 
$\dot{M}$ uch difference of opinion has existed on the subject of the union of the fractured neck of the thigh bone. It has been asserted that these fractures unite like those of other parts of the body; but the dissections which I made in early life and the opportunities I have since had of confirming these observations, have convinced me that fracture of the neck of the thigh bone, of the patella, olecranon, condyle of the os humeri, and of the coronoid process of the ulna generally unite by ligament and not by bone. This principle I taught in my lectures for thirty years: and it is a most essential point, as it affects the reputation of the surgeon, as well as being a subject of some interest in forensic medicine; for if these fractures unite like those of other parts of the body, the patient who remains lame after the treatment would undoubtedly have a right to such redress from the surgeon at the hands of the law.

Nothing is known in our profession by guess; . . . it is right, therefore, that those who are studying their profession should be aware that there is no short road to knowledge: that observation upon the diseased living, examinations of the dead, and experiments upon living animals are the only sources of true surgical knowledge and that indications from these are the sole bases of legitimate theory.

In the examinations which I have made of transverse fractures of the cervix femoris entirely within the capsular ligament, I have only met with one in which a bony union had taken place or which did not admit of a motion of one bone upon the other. To deny the possibility of this union, and to maintain that no exception to the general rule can take place, would be presumptuous . . .

Much trouble has been taken to impress the minds of the public with the false idea that I have denied the possibility of union of the fracture of the neck of the thigh bone: and I therefore beg at once to be understood to contend for the principle only, that $I$ believe the reason that fractures of the neck of the thigh bone do not unite is, that the ligamentous sheath and periosteum of the thigh bone are torn through, that the bones are consequently drawn asunder by the muscles, and that there is a want of nourishment of the head of the bone, but I can readily believe that if a fracture should happen without the reflected ligament being torn, that as the nutrition would continue, the bones might unite: but the characters of the accident would differ; the nature of the injury could scarcely be discerned, and the patient's bone would unite with little attention on the part of the surgeon.

Cause of the want of union, first, is the want of proper apposition of the bones, for if in any part of the body the extremities of a broken bone be kept asunder ossific union will under ordinary circumstances be prevented . . .

The neck of the thigh bone, when broken, is placed under similar circumstances (to the fractured patella) for, by contraction of the muscles it is no longer in apposition with the head of the bone and is therefore prevented from uniting; if this, however, were the only obstacle, it might be argued that the retraction of the thigh bone could be prevented by bandaging and extension, the truth of which cannot be denied; but it is scarcely possible, even for a few hours, to preserve the limb in exact apposition, as the patient, on the slightest change of posture, produces instant retraction by bringing into action those powerful muscles, which pass from the pelvis to the thigh bone . . .

A second circumstance which prevents the bony union of these fractures is want of pressure of one extremity of the broken neck upon the other, even though the limb preserves its length, and the fractured parts are consequently 
not much displaced. This want of pressure may arise in some degree from the excessive secretion of serous synovia which follows the accident; but principally from the action of the muscles which separate the bony surfaces.

A third reason which may be assigned for the general want of union of this fracture is the almost entire absence of nutrition in the head of the thigh bone when separated from its cervix, its life being supported by the ligamentum teres, which has only a few minute vessels ramifying from it to the head of the bone.

The fourth reason is . . . want of constitutional vigor which always accompanies old age.

It seems strange that a Fellow of the Royal Society, who could so clearly summarize the results of his observations, did not accomplish the final step in his reasoning-that all the obstacles enumerated against repair were due simply to lack of command of an effective treatment. But in Sir Astley's day the neck of the femur was not the only bone "generally uniting by ligament." It shared the burden with the "patella, the olecranon, the condyles of the os humeri, and the coronoid process of the ulna." One by one, as the science of treatment, particularly in the sphere of open operation, progressed, these other bones have been shown, when their fractured surfaces have been placed and held in apposition, to be capable of bony union.

In 1904, it was demonstrated that under favorable circumstances the neck of the femur might also so unite. In other words, a proper form of treatment was for the first time described. ${ }^{3}$ Originally devised for the treatment of fractures in children, or in young and vigorous adults, its application has been gradually expanded until now it has been successfully applied to all classes of cases.

That this treatment has not been widely adopted is a source of surprise and regret to those familiar with it. The present status of treatment of fractures of the neck of the femur is evidenced by the subjoined quotation : ${ }^{4}$

After carefully reviewing the case records of these patients, the outstanding points established were that the nonunion in the majority resulted from an incorrect diagnosis at the time of accident, and that in the minority, even when the proper diagnosis had been made, no treatment had been carried out, often, it is true, for some justifiable reason. In a certain few, the measures used had been rather in the form of a surgical ritual and were not in any sense of the word adequate. It was astonishing to ascertain how often elderly persons, who after a severe fall were disabled on account of intense pain in the hip, were told without being carefully examined that they were suffering from a sprain, the fracture not being diagnosed until months later, usually by

3. Whitman, Royal: A New Treatment for Fracture of the Neck of the Femur, Med. Rec. 65:441, 1904.

4. Henderson, M. S.: Ununited Fractures of the Hip, Surg., Gynec. \& Obst. 30:145 (Feb.) 1920. 
another consultant. Another somewhat common story was that the physician who was called in carefully measured the legs and finding no shortening or eliciting no crepitus, diagnosed a sprain without resorting to radiography. Weeks or months later a consultation necessitated by continued disability revealed shortening of the affected leg, crepitus on manipulation, and a roentgenograph established the diagnosis of fracture. The probable explanation of this is that what was originally a more or less weakly impacted fracture broke down through inadequate fixation of the limb. In none of the cases in this series was there a history of really proper treatment for the fracture. Good treatment had been instituted in a few instances, but for some reason it was not prolonged enough. The patient may have been unruly, the supervision too weak, or complications, such as impending pneumonia, may have necessitated a discontinuance of treatment.

\section{CAUSES FOR FAILURE TO APPLY THE ABDUCTION METHOD}

Such a state of affairs should not be allowed to persist, and this article is an inquiry into the causes for failure to adopt the only proper method of treatment for a crippling injury. I have quoted, and used as texts for comment, excerpts from several authors. This is not done in a spirit of criticism. The quotations are offered as fairly reflecting the general attitude toward the treatment of the injury, which is notable chiefly for its lack of any general standard, either in methods to be applied or results to be expected. To illustrate this haziness, I have taken three passages from a recent monograph. ${ }^{5}$ The author begins his article, a description of a splint he has devised, with a few home truths:

1. Experience has taught that these patients (suffering from fracture of the neck of the femur) bear confinement in bed and the presence of cumbersome dressings very badly.

2. Probably most surgeons treat these cases with sandbags and extensions. Imperfect rigidity of the parts is thus obtained.

3. Plaster bandages enclosing more or less of the trunk and the thigh are used by many.

If one were to read these statements and apply them to a patient suffering from a fracture of the shaft of the femur, what would be the impression of the quality of the treatment that that particular class of patients was receiving? Who would keep a patient suffering from a fracture of the shaft of the femur flat on his back, unable to move because of sandbags, making whatever movements he did at the cost of excruciating pain, because of the "imperfect rigidity of the parts thus obtained"? Who, if he used plaster, would use it "enclosing more or less of the trunk and thigh"? Would not the most charitable comment on such treatment be that the one who used it was a little uncertain in his mind as to the principles of the

5. Masland, H. C.: A Form of Splint Available in the Treatment of Fractures of the Neck of the Femur, Ann. Surg. 71:501 (April) 1920. 
treatment he was trying to apply? Certainly one would not be overoptimistic as to the result to be expected. On the basis of such treatment one would scarcely feel justified in making the statement that fractures of the shaft of the femur were a class of cases not adapted to the application of surgical principles, and that the surgeon in charge of such a case was to be congratulated if he succeeded in saving his patient's life. In short, one would say that the surgeon was blaming Nature for the natural consequences of his improper treatment.

Has not this been the attitude of surgeons in general for the past hundred years toward fracture of the neck of the femur?" Because such fractures "occur most commonly in elderly persons," and because surgeons have not had at their command means for the application of such surgical principles as they would at least attempt to apply in the treatment of any other fracture, have they not been prone to excuse their universally bad results on the ground of "lowered vitality and structural weakening of the part"?

I think it may now be conceded that authorities on the subject of fractures are agreed that the treatment of fractures of the neck of the femur by the abduction method is the only method that applies, or attempts to apply, surgical principles to that form of injury. ${ }^{i}$

Under anesthesia initial manual traction on the affected limb overcomes shortening. Full abduction and slight inward rotation places the fragments in apposition and restores the normal angle described by the neck of the femur with the shaft. Full abduction of the thigh on the pelvis holds the fragments in position by tension of the capsular ligaments and relaxation of the muscles whose contraction tends to produce overriding of the fragments. What is most important, it assures the mutual pressure of the fractured surfaces, which was insisted upon by Sir Astley Cooper as being essential to repair. In combination with full abduction, hyperextension of the thigh on the pelvis is an additional safeguard against the force of gravity in preventing dorsal displacement of the distal fragment (Figs. 1, 2, 3 and 4). Any one who has performed an open operation on such a fracture has had the opportunity to verify these facts by his own observation.

6. Cotton, F. J.: Ann. Surg. 63:366 (March) 1916.

7. Albee, F. H.: Orthopedic and Reconstruction Surgery, Philadelphia, W. B. Saunders Company, 1919, p. 600 . Tubby, A. H.: Deformities, Including Diseases of the Bones and Joints, London, the Macmillan Company 1:595-601, 1912. Judet, H.: Traité des Fractures des Membres, Paris, A. Maloine; 1913, p. 356. Scudder, C. L.: The Treatment of Fractures, Ed. 8, Philadelphia, W. B. Saunders Company, 1915, p. 422; A System of Surgery, New York, Funk \& Wagnalls Company 3:648, 1914. DaCosta, J. C.: Modern Surgery, Ed. 8, Philadelphia, W. B. Saunders Company, p. 673. 
Indeed, to any one who has done so the proposition seems so simple and self-evident that he is inclined to wonder at the slow general progress that has been made toward its adoption.

I take it that the majority of surgeons are conscientiously interested in the welfare of their patients, and that we may not ascribe the lethargy of the profession toward the adoption of a new principle either to stupidity or to laziness. One is therefore bound to inquire what the further causes of such a condition may be. Having pointed out a theoretical truth, we may not yet be satisfied if almost universal human fallacies prevent its application. To use a homely illustration, we have not done our duty during a smallpox epidemic if we content ourselves with recommending vaccination. We must see that the vaccination takes. What, then, are the causes militating against the application of the abduction treatment of fracture of the neck of the femur?

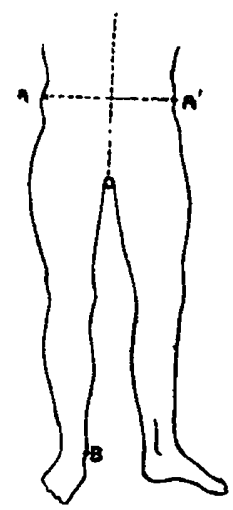

Figure 1

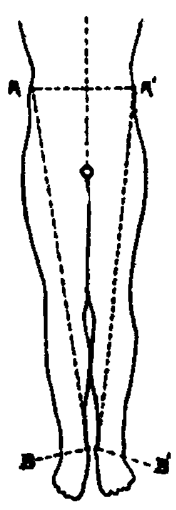

Figure 2

Fig. 1.-Attitude of the limb in fracture of the neck of the left femur.

Fig. 2.-Limbs parallel: traction on the affected limb has overcome shortening. Distance $\mathrm{A}^{\prime} \mathrm{B}^{\prime}$ must equal distance $\mathrm{A} B$.

The first is the general atmosphere of discouragement surrounding the patient. He, or she, is old, frequently fat, often, when first seen, already suffering from hypostatic congestion of the lungs, which after a time may become an edema causing death. There is usually a suspicious redness over the sacrum, and the nurse, or family, complains that it is next to impossible to keep the patient clean, because of the protests that she makes at any attempts to change her position. The picture is one to make the most optimistic surgeon shudder. If the patient dies untreated the death will be regarded by the family as an act of God, and frequently as one for which they are most 
grateful. Such a death is commonplace. There is no community that is not familiar with the story of more or less legendary great uncles and aunts who "broke their hips," and died after varying degrees of suffering. If the surgeon applies treatment other than the generally accepted ritualistic sandbag, particularly the proverbial instrument of torture known as the "plaster cast," and the patient dies, he and his treatment will receive full blame for the death. The relatives will forget the agony of the patient, and regret only that her presence could not have been vouchsafed them for a few weeks longer. Is it any wonder, then, that a surgeon should hesitate to apply a treatment of the soundness of which he may be theoretically convinced, but which very likely he has never seen applied? Can we blame him too severely for expatiating on the notorious unwillingness of such fractures to unite, of the necessity for making the patient as com-
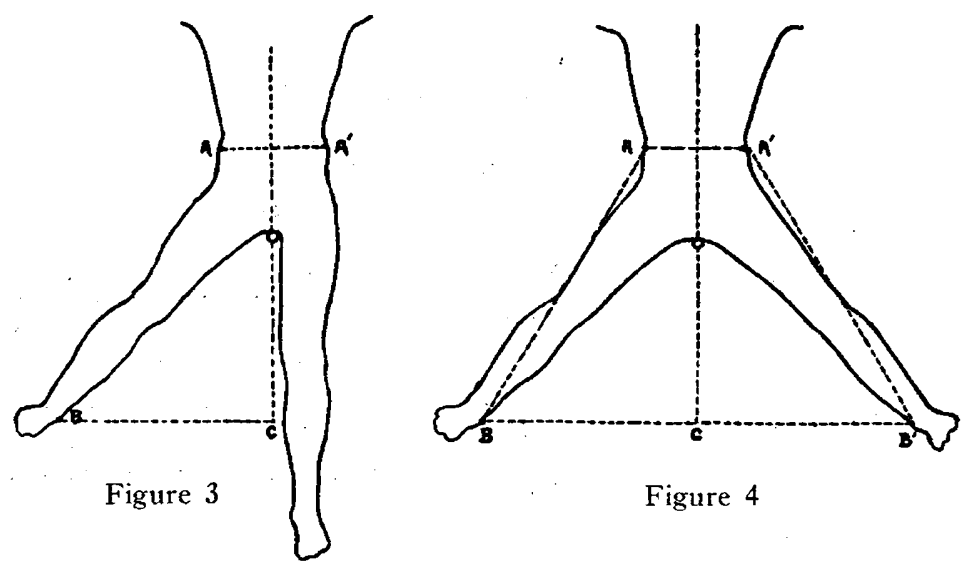

Figure 4

Fig. 3.-Abduction of the sound limb to the normal limit.

Fig. 4.-With traction maintained, the affected limb is abducted to correspond to the normal. Angle $B^{\prime} O C$ must equal angle $B O C$; distance $A^{\prime} B^{\prime}$ must equal $\mathrm{A} B$.

fortable as possible, and of getting her out of bed immediately to avoid pneumonia? In such a course he is supported by tradition, and he will add to his reputation as a "sound conservative."

In this connection, I hope that I may not be accused of levity if I use the following incident as an illustration: During a clinic which I was holding on infantile paralysis in New York State I heard one physician say to another that a child in a far, outlying district had just died of "black measles." I asked what "black measles" were. "Why, Doctor," was the answer, "it's a peculiar disease we sometimes have around here. Only Dr. Smith's patients have it. He 
makes the diagnosis, all the families hereabout know it's fatal, so when the patient gets no treatment and dies of 'black measles' everybody's satisfied."

The second cause for the failure to apply the abduction method is that when Dr. Whitman originally described its theory ${ }^{3}$-its basic anatomic principles-he also described its application by the use of the long plaster-of-Paris spica. I am seriously inclined to believe that this was unfortunate. Had the treatment been described solely by anatomic demonstration and its practice left to the individual, the grasp of the theory might not have been overshadowed and interfered with by the difficulty of a particular method of its application. So great has this confusion become that I have frequently heard the abduction treatment referred to as the "plaster treatment." It is not a plaster treatment. The means of its application are a detail, and vary according to the individual predilections of its employers. Sir Robert Jones ${ }^{8}$ uses an abduction frame. Dr. McGlannan ${ }^{9}$ of Baltimore includes both thighs. Dr. Scudder ${ }^{7}$ of Boston puts the limb in a flexed position. Judet ${ }^{7}$ of Paris uses the "gouttière de Bonnet." These are methods that are much at variance, but that are sound because those that employ them have a definite idea of what they are trying to do, and why they are trying to do it.

There is an impression current among the profession that anybody can apply plaster of Paris. The corollary of this proposition is that plaster of Paris is uncomfortable. As a matter of fact I know of nothing in surgery which requires more practice, or is more difficult, than to apply a comfortable plaster-of-Paris dressing. And of all plaster-ofParis dressings there is none more difficult to apply properly than a long spica, extending from the axillae to the toes, in which the patient must live for a period of weeks. After having applied such a dressing, one has then to combat the obstinacy of the entire nursing profession. That profession, too, has its traditions, of which one of the most firmly grounded is that patients encased in plaster are as immovable as the Rock of Gibraltar, and must lie in changeless discomfort until they dit: of bedsores. Any suggestion that the patient be moved at all, much less turned on the face, is met by a gasp of horror. As a matter of fact, however, and I have even had this sheepishly admitted to me by a broken-spirited attendant, it is easier to turn a patient, even with the added weight of plaster, when turning does not cause him pain, than

8. Jones, Robert: The Oxford Surgery, New York, Oxford University Press, 1918, p. 805.

9. McGlannan, A.: Fracture of the Neck of the Femur, Surg., Gynec. \& Obst. 22:287 (March) 1916. 
when every movement causes discomfort, sometimes bordering on agony.

Provided the plaster has been properly applied, it should be comfortable and strong enough to permit of the patient's being freely moved about. He should be turned on his face every day, as well as from side to side, and this constant shifting of position is the most certain preventive of bedsores. ${ }^{10}$ Unless the nurse's hand is exceptionally large, she will find it quite possible to introduce it under the plaster and give the back its daily massage.

The objection is being continually made that the "treatment is so confining." This is quite true, but I know of no treatment of what may be called a major fracture, that is not confining. Indeed, since the war, we have capable advocates of the treatment of all fractures of long bones by traction and suspension. At a recent lantern slide demonstration of this technic, ${ }^{11}$ I heard one enthusiastic convert remark that "Dr. Blake's demonstration had sounded the death knell of the treatment of fractures by plaster of Paris." What those who object to the confining element of treatment really mean is that they fear to try any treatment at all, and, neglecting the fracture entirely, wish to get their patients up and about as soon as possible. This attitude is perfectly reasonable provided its advocates make it clear to themselves and their patients that they are abandoning all thought of functional recovery and are preserving for them a future of permanent lameness and discomfort.

As a matter of fact, in many cases, the treatment need not be exceptionally confining. A degree of activity is possible directly in proportion to the temperament-adventurous or otherwise-of the patient. I have already said that all patients should be turned on their faces daily for a varying period, and of course all patients should have the heads of their beds raised to avoid the danger of hypostatic congestion. From this as a minimum, one may proceed as far as having the patient up and out to drive. If the splinting apparatus be properly applied, movement causes no pain, and the difficulties of movement become purely mechanical and subject to the strength and ingenuity of the patient. One woman now under treatment at her own home, after remaining at the hospital for one week, had her husband sling a pole from the head to the foot of her

10. Whitman, Royal: The Abduction Treatment of Fractures of the Neck of the Femur, with Especial Reference to the Semireclining Posture and Changes in the Attitude in Its Application to Elderly Subjects, Ann. Surg. 53:489 (April) 1911.

11. Whitman, Royal: The Abduction Treatment of Fractures of the Neck of the Femur, Med. Rec. 97:585 (April 3) 1920. 
bed, over which a rope was passed and made fast to the leg of the plaster. With this primitive block and tackle she was able to change her own position at will. Another energetic Jewish woman, aged 64, at the Hospital for the Ruptured and Cripp!ed, insists on being propped up in a wheel chair every day. Insane patients, who could not be treated in any other way, have as a last resort been, as it were, boxed up in plaster of Paris by the abduction method and have made perfect functional recoveries. Sir Robert Jones, indeed, goes so far as to say, "Where hypostatic troubles may be expected, plaster of Paris has advantages over any kind of splint, for the patient need not be confined to bed." 8

To quote again from the article which is serving for my text, speaking of the application of a plaster spica upon a pelvic rest, the points of support being the sacrum and the shoulders, the author says, "The vertebra [sic] are sagging in the middle with the spines projecting more than they naturally do. This factor... . explains the great discomfort frequently experienced and the fact that bedsores are not uncommon." If plaster, or any support, be applied in this position, the consequences to which the author alludes are to be expected. One must be most careful to guard against this by full extension of the thighs. upon the pelvis, thus tilting the pelvis forward, and by manual support if necessary, or the insertion of a pad or pillow, to assure the maintenance of the normal lumbar lordosis. It is the flat back, the result of the sagging of the spine following prolonged confinement in bed, that is the cause of so much discomfort, and sciatic pain. ${ }^{12}$ How much worse if the patient be immobilized in this position. The quotation is a perfectly justified criticism of an improperly applied support. I should imagine also that this danger of the flat back, obliteration of normal lordosis, would have to be particularly guarded against if the patient were put up with the thighs flexed on the pelvis.

A third reason for the failure of the general application of the treatment is the neglect of surgeons to carry out its elementary anatomic details. For this I confess I can find no satisfactory explanation. On one occasion, I demonstrated the application of the method on two patients to the interns of a general hospital, to their apparent understanding and satisfaction. A short time after, I returned to find two other patients to whom they proudly stated the method had been applied. The affected limbs were possibly in 15 degrees of abduction, the body portion of the plaster was so short that it dug into the

12. Goldthwait, J. E., and Osgood, R. B.: A Consideration of the Pelvic Articulations from the Anatomic: 1, Paihological and Clinical Standpoint, Boston M. \& S. J. 152:593; 634, 1905. 
patients' short ribs, causing them continual discomfort, and the plasters had both broken at the groin. At times one might really be led to suppose that surgeons do not know what abduction is. This may be evidenced by Figures 5, 6 and 7 , taken from a most interesting article. $^{13}$ Abduction is a motion taking place at the hip joint and not one of the patients photographed shows any abduction whatever. They are simulating abduction by tilting the pelvis. Nor do surgeons understand why abduction is important, and they are inclined to regard the insistence on the position of full abduction as an idiosyncrasy of a faddist. Full abduction is important for these reasons: It anatomically restores the alinement of the fractured bone and assures mutual pres-

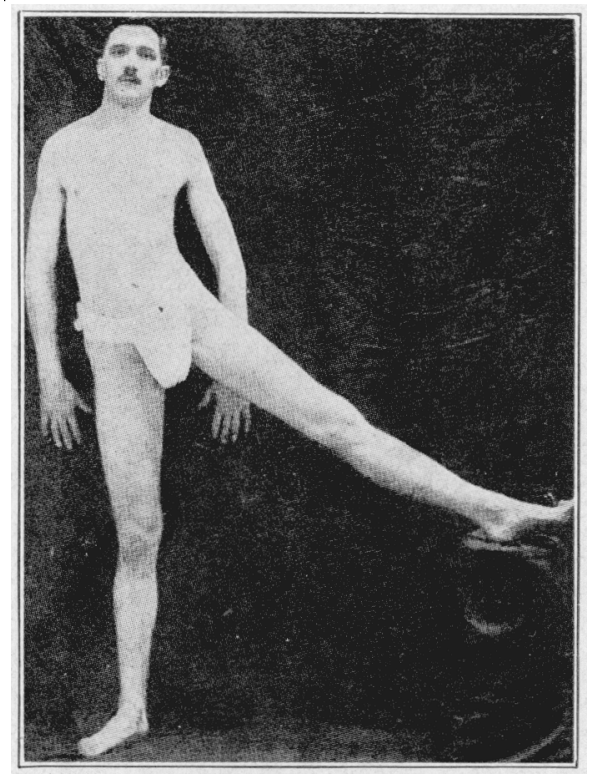

Fig. 5.-Simulation of abduction by tilting of the pelvis. The patient shows no abduction whatever. (Illustration taken from an article by another author.)

sure of the fragments upon one another. Full abduction is necessary to assure internal splinting, by forcing the proximal fragment within the acetabulum, maintaining tension on the capsule, and bringing the trochanter in contact with the rim of the acetabulum. After the bone has united the patient can walk without a limp. A normal range of abduction is as essential to a normal gait as is that of flexion or extension. The secret of the indifference displayed toward this

13. Davison, Charles: Transplantation of Bone for Defects of the Head and Neck of the Femur, Surg., Gynec. \& Obst. 29:142 (Aug.) 1919. 
detail lies in the fact that surgeons are astonished and gratified to have such a patient walk at all. As a criterion of success to demand that he walk with comfort or without a limp would be regarded as chimerical.

Indeed, I am sorry to say that in the general literature on the subject, the clearest and most concise statement of why abduction is essential comes from a French author, Dr. Judet: ${ }^{\top}$

Elle (traitement) doit viser à rétablir à la fois la forme et la fonction. Il est d'ailleurs reconnu aujourd'hui que la seconde ne peut être parfaite si la première est très defectueuse.

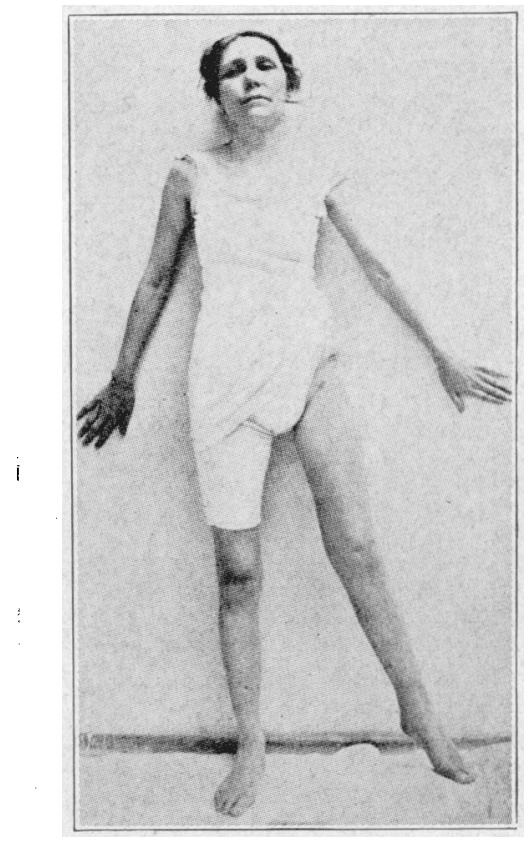

Fig. 6.- Simulation of abduction by tilting of the pelvis. The patient shows no abduction whatever. (Illustration taken from an article by another author.)

Treatment should aim to reestablish, at the same time, form and function; it is, however, recognized today that the second cannot be perfect if the first is defective.

Evidently in France it is not considered a "crime to disturb impaction" with a view to the improvement of function, nor is the surgeon satisfied if he has succeeded in obtaining union with the bones in unsatisfactory position.

Another cause for failure lies in improper after-treatment. As Henderson ${ }^{4}$ says, in speaking of the cases in his series, "Good treatment had been instituted in a few instances, but for some reason it 
was not prolonged enough." Here again surgeons at large do not seem willing to face the fact that weight should not be borne on the affected limb for six months after the injury. This seemingly excessive caution is due to these reasons: first, the slowness of repair of intracapsular fractures; second, the peculiar situation of the injury, the body weight falling directly across the line of fracture. I suppose the reason for not considering these facts and for the tendency to allow early weight bearing with the consequent grave risk of refracture, or the development of the deformity of coxa vara, is that to

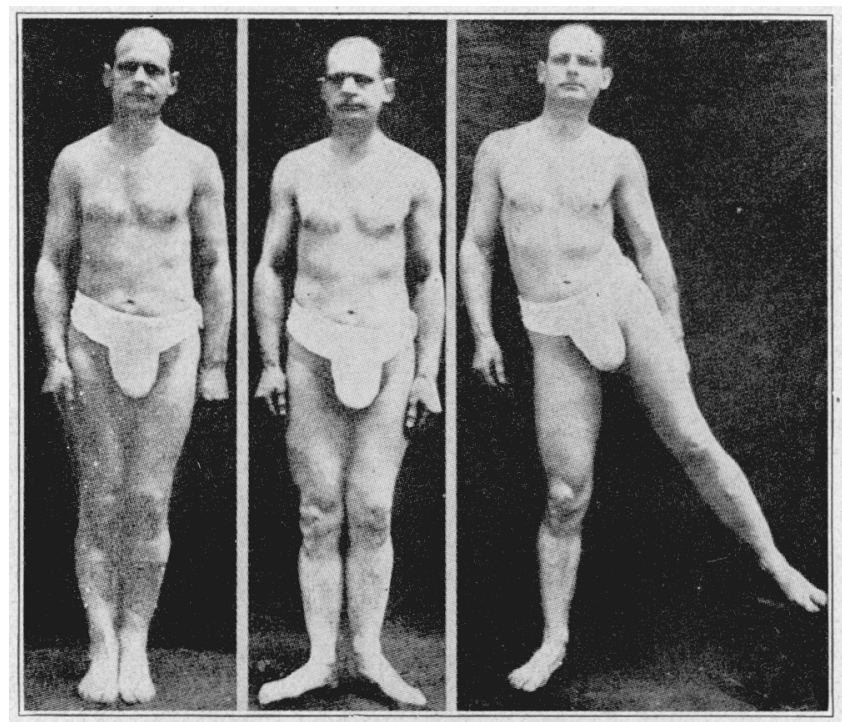

Fig. 7.-Simulation of abduction by tilting the pelvis. The patient shows no abduction whatever. (Illustration taken from an article by another author.)

most people non-weight-bearing means lying in bed, or at least getting about on crutches. This is not necessary, as the caliper hip splint will allow fairly comfortable locomotion. ${ }^{14}$ It is possible to employ the Thomas splint for the same purpose, though it is not nearly so comfortable. Even if neither of these methods is practicable, I think the average patient would prefer six months' inaction to a permanently damaged and probably painful limb.

\section{SUMMARY}

The causes militating against the proper treatment of fracture of the neck of the femur would seem, then, to be these: (1) the tremendous force of surgical tradition to the effect that any treatment

14. Whitman, Royal: A Treatise on Orthopedic Surgery, Ed. 6, Philadelphia, Lea \& Febiger, 1919, p. 555. 
is useless; (2) the fact that the majority of such injuries occur in subjects that are not in any respect attractive to the surgeon; (3) lack of clear understanding of the anatomic principles of the abduction treatment; (4) the unfamiliarity of the average surgeon with the use either of plaster of Paris or the manufacture and application of other retention apparatus; (5) lack of appreciation of the necessity for the restoration of the normal form and structure of a bone if normal function is subsequently to be expected, and (6) a neglect of proper after-treatment, and the lack of insistence on detail.

In a paper such as this, and in any inquiry into failure, it is very difficult not to seem hypercritical, and I can imagine many readers laying this aside with the impression that the emphasis throughout had been on criticism, and perhaps on criticism of individuals. I hope that such will not be the case. In any walk of life there are certain facts that must be faced, and one of the most glaringly unpleasant in the surgical world is the wretched lot of the average patient with a broken hip. None of the obstacles to failure that I have enumerated is insuperable.

No one, unless self-deluded or a liar, will pretend that a certain treatment can be applied in all cases, or that all patients may be cured. What $I$ hope to see in the immediate future is the wider recognition of the fact that a fracture of the neck of the femur is a fracture like any other fracture, even though it often occurs in subjects that one would not be anxious to treat for any complaint whatever; also that the same standards of treatment and the same judgment of results should be applied to this fracture as to any other.

- Surgeons can no longer shelter themselves behind the age-long superstition to which Sir Astley Cooper one hundred years ago did not subscribe, that intracapsular fractures of the neck of the thigh bone will not unite under any form of treatment. If they do not care to apply treatment in a given case they must explain to those concerned that the character of the patient makes it inadvisable to treat the fracture, not that the character of the fracture makes it inadvisable to treat the patient. 